\title{
REFLEXÕES ACERCA DO DESENVOLVIMENTO DA AUTORIA NO \\ EXERCÍCIO DE ESCRITA ENVOLVIDO NA ANÁLISE TEXTUAL DISCURSIVA: UM HORIZONTE COMPREENSIVO
}

\section{REFLECTIONS ABOUT AUTHORSHIP DEVELOPMENT IN WRITING RELATED TO THE DISCURSIVE TEXTUAL ANALYSIS: THE COMPREHENDED HORIZON}

\author{
Vivian dos Santos Calixto ${ }^{1}$
}

\begin{abstract}
Resumo: Neste texto abordam-se algumas reflexões, aprendizagens e compreensões acerca do processo de apropriação teórico/metodológico da Análise Textual Discursiva (ATD). Nesse interím, tencionou-se compreender a potência da ATD no percurso de constituição do vir a ser professor/pesquisador e no desenvolvimento de sua autoria. Como material empírico foram analisadas as escritas provenientes dos diários de pesquisa que acompanham a pesquisadora, autora desse texto, desde sua graduação e seus textos de pesquisa. Como compreensões pode-se mencionar a relevância do processo de apropriação teórico/metodológico da ATD como potência no percurso constitutivo do vir a ser professor/pesquisador. Nesse contexto a sensibilidade e a escrita se aproximam em termos de aprendizagem, por meio desse movimento a elaboração de metaforas aflora. Dessa amalgama, entre apropriação da ATD, desafio de escrita constante e desenvolvimento da sensibilidade a autoria do pesquisador é delineada de forma progressiva, rumo a um entendimento mais profundo e intenso dos fenômenos investigados.
\end{abstract}

Palavras-chave: Análise Textual Discursiva; Autoria; Metatexto.

Abstract: This text addresses some reflections, learning experiences and views of the process of theoretical/methodological appropriation of the Discursive Textual Analysis (DTA). It aims at understanding the strength of DTA in the journey of becoming a teacher/researcher and in the development of its authorship. The empirical material comprises writings from the author's research diaries which have been kept since her graduation course. Relevance of the process of theoretical/methodological appropriation of the DTA as strength in a teacher/researcher's constitutive journey should be mentioned. In this context, sensitivity and writing get together in terms of learning, a movement that make metaphors develop. In the intertwinement among appropriation of DTA, the challenge of constant writing and development of sensitivity, the researcher's authorship is progressively outlined towards deeper and more intense understanding of phenomena under investigation.

Keywords: Discourse Textual Analysis; Authorship; Metatext.

\section{Portos de partida...}

Olho, indecisa, para as ondas e para as pontes que desafiam meus limites cognitivos. Vejo nelas o meu próprio reflexo. Serei capaz de me descolar desses fenômenos para estudá-los? Estando imbricada neles, qual estratégia permitirá visualizá-los? (KNOBBE, 2014, p. 39).

\footnotetext{
${ }^{1}$ Licenciada em Química e Mestra em Educação em Ciências pela Universidade Federal do Rio Grande (FURG). Doutora em Educação para a Ciência e a Matemática pela Universidade Estadual de Maringá (UEM). Professora Adjunta na Universidade Federal da Grande Dourados (UFGD). Líder, em conjunto de Adriana Marques de Oliveira, do grupo de pesquisa: Grupo de Estudos e Pesquisa Horizontes Compreensivos na Educação em Ciências e Química - (GEPHCECQ). Dourados, Mato Grosso do Sul, Brasil. E-mail: viviancalixto@ufgd.edu.br
} 
Nosso itinerário de compreensão percorrerá distintos momentos que constituem o percurso de constituição da professora/pesquisadora, que redige as palavras expressas nesse texto, em conjunto das experiências com a Análise Textual Discursiva (ATD). Não seguiremos, necessariamente, uma ordem cronológica linear, perpassaremos distintos momentos, em dimensões que provocam um repensar do tempo Chronos e Kairós. O tempo da experiência será a nuance adotada em nossa conversa, ou seja, como o processo, complexo, de transformar vivências em experiências oportunizou a construção das reflexões, entendimentos e compreensões expressas aqui.

Como argumento central neste texto pretende-se defender a conexão/relação entre as aprendizagens oportunizadas via exercício da ATD e o desenvolvimento da autoria do pesquisador. Ao vivenciar os desafios oportunizados pelos momentos que constituem a ATD, unitarização, categorização e elaboração do metatexto, o pesquisador é questionado e provocado a colocar em suspensão suas certezas e, em meio ao "caos e ordem", encontra no processo de escrita um oásis para organizar seus pensamentos. Compreendo, nesse momento, que além de uma metodologia de análise de informações discursivas, a ATD desafia, por meio de distintos movimentos, o pesquisador a aprender a escrever. Escrita com autoria, permeada pela análise crítica, pela fusão do horizonte do pesquisador com o texto que tenciona compartilhar com os demais leitores, que não ele próprio.

Nas conversas que têm como foco a ATD, de forma recorrente, emergem questionamentos acerca de seus princípios, diferenças entre a ATD, a Análise de Conteúdo e Análise de Discurso, o que é o metatexto, as possibilidades em termos de categorização, emergente ou a priori, dentre muitas outras que nesse momento não me recordo. Ao perpassar distintos contextos formativos, deparei-me com dúvidas e questionamentos acerca dessas nuances. Diante dessa conjectura, por meio desse texto, abordarei algumas dessas dimensões de forma interligada às experiências relatadas em meus diários de pesquisa, produzidos em minhas investigações de Trabalho de Conclusão de Curso (TCC), mestrado e doutorado. Além de unidades de significado dos textos de pesquisa produzidos nesses espaços, respectivamente da Monografia, da Dissertação e Tese.

Para esse desafio, busquei inspiração na obra produzida por Margarida Maria Knobbe, mais especificamente no livro de título "O que é compreender?: viajando com Gulliver por velhos e novos mundos, em companhia de Edgar Morin, Hans-Georg Gadamer, Maria da Conceção Almeida e outros pensadores de diversas áreas do conhecimento" (KNOBBE, 2014). Nele a autora se desafia a compreender o que seria a 
compreensão, para tanto desenvolve um exercício de escrita, no formato de diário, em que recorre a autores de distintas áreas como aportes para potencializar o processo. Sua escrita se estrutura por meio de narrativas, nas quais avança no percurso de compreensão parando em portos, reabastecendo e partindo rumo a novos horizontes.

Inspirada em seu trabalho, desafiei-me a escrever esse texto, revisitando meus diários, produzidos ao longo de meu percurso constitutivo enquanto professora/pesquisadora, e as experiências que tenho construído por meio das vivências oportunizadas em diferentes espaços e tempos que tenho percorrido. Como elementos e argumentos constantes nesse processo percebo, atualmente, a compreensão da potencialidade da escrita no processo de constituição do vir a ser professora/pesquisadora e a ATD como uma metodologia potente no desafio de aprender a escrever, compreender e construir argumentos, dimensões especialmente relevantes para aqueles que se centram na pesquisa de natureza qualitativa.

Quando expresso a compreensão de que a ATD se delineia como um elemento potente nesse exercício e desafio constante de escrever, compreender e argumentar, ancoro-me no entendimento de vir a ser. Com isso, pretendo argumentar acerca da compreensão de que à medida que me aproprio do exercício de escrita e compreensão que constituí a ATD posso ampliar meus horizontes, perceber nuances, cores e zonas ainda não percebidas, estou em constante movimento de me tornar mais. Diante desse contexto as palavras de Pereira (1996, p. 40) me inspiram e auxiliam:

\footnotetext{
Tomado dessa forma, passamos a compreender o sujeito como localizado no extremo da subjetividade e, portanto, prenhe de devires. Um sujeito-em-prática é o que está sendo e, ao mesmo tempo, potência de vir a ser outro de si, algo diferente do que vem sendo, algo nunca sido. Assim, observamos que o sujeito é sempre potência. E esse estado de tensão constante, esse risco permanente de desfazer-se é algo muito distinto de identidade. Uma identidade é a institucionalização de uma forma, é a redução do movimento de criação à reprodução de modelos hegemônicos e estereotipados.
}

Tive contato com a pesquisa desenvolvida pelo professor Marcos Villela Pereira em meu mestrado, nela o autor constrói argumentos acerca do conceito de professoralidade e da sua correlação com a estética. Esse exercício propõe três jogos de trilha, que se ancoram em conceitos da formação de professores e do processo constitutivo do mesmo, e que tencionam problematizar o desenvolvimento da professoralidade. Como argumento, acerca da professoralidade, elucida que:

Vir a ser professor é projetar-se num estado quase estável de si, no interior de uma determinada prática profissional de modo que ele venha a ser um agente propositor de experiências que catalisem incursões em direção ao si-mesmo. 
Que a prática pedagógica e a rotina escolar, sejam, a um só tempo, um impulso e uma rede (PEREIRA, 1996, p. 3).

A compreensão, construída pelo autor supracitado, ampliou meus horizontes acerca da relação entre a dimensão estética e o processo de vir a ser professor. Foi um abastecimento muito relevante, uma parada em um porto da estética e da professoralidade, que oportunizou uma compreensão fundante no percurso que tenho desenvolvido em busca de compreender o processo de vir a ser professor, mais especificamente na área da Educação Química. Vir a ser professor envolve distintas nuances, vivências e experiências. Não se delineia como uma rota pré-determinada, seguida rigorosamente da mesma forma por todos. Temos nossos tempos, experienciamos espaços, encontramo-nos com pessoas diferentes e transformamos vivências em experiências de maneira única, singular, constituídos pela subjetivade característica de cada um de nós.

Um outro momento relevante, quando considero os portos em que passei até aqui, foi o desenvolvimento do TCC. Como comentei no íncio desse texto, a ordem cronológica não será seguida aqui. Nesse sentido, após reviver rapidamente uma aprendizagem significativa, um horizonte ampliado, na dissertação, revisitarei a experiência do TCC. A primeira incursão na pesquisa, na área da Educação Química e com a ATD.

Como uma das maiores aprendizagens nesse espaço/tempo posso mencionar a apropriação teórica acerca da potencialidade epistêmica da escrita, mais especificamente por meio da obra "Escrever é preciso: o princípio da pesquisa" de autoria de Mario Osorio Marques (MARQUES, 2008). Em seu texto, o autor argumenta acerca da relevância de escrevermos para pensar, rompendo com a lógica, predominante, de que primeiro lemos e pensamos para só após escrever. Como compreensão acerca da potencialidade da escrita e dos movimentos inerentes a esse processo, o autor menciona:

Por isso escrever é preciso para encontrar-se a si mesmo sendo mais forte do que se é, para a longa e tortuosa busca do Outro de um desejo mais paciente. Importa em duplo desconhecimento: o do que somos e podemos e o de outrem que misterioso nos guarda. Trabalho pela dúvida inaugural da criação, o escrevente busca achar-se, desenvolver-se, dizer-se para além das circunstâncias imediatas (MARQUES, 2008, p. 45).

A intencionalidade em compreender o processo de vir a ser professor se manteve constante em meu percurso, orientou as viagens e paradas nos diferentes portos. Em conjunto a compreensão da escrita como ferramenta potente nesse processo, escrevendo para pensar, aprender e orientar o percurso. Ambas me acompanharam no desafio do doutorado, orientaram e estruturaram minhas opções de investigação. 
No TCC, a questão de pesquisa se centrou em "Qual a importância/influência da escrita na constituição do professor de Química?", no mestrado a questão se relacionava a "Como nos tornamos professores-pesquisadores ao desenvolver pesquisa na disciplina de monografia no curso de Química - Licenciatura da FURG? ", na tese, por sua vez, “Como nos constituímos professores de Química por meio do desenvolvimento de ações que objetivavam a construção de uma crítica fundamentada ao ensino por transmissão no espaço de componentes curriculares com carga horária integral de PCC?”. As aprendizagens foram se ampliando, horizontes compreensivos foram sendo construídos e alargados, mas uma grande questão esteve constante em todas as investigações: como nos constituímos professores? Como referencial teórico/metodológico, constante em todos esses momentos, a ATD.

E foi no doutorado que compreendi, de forma mais intensa, o papel da ATD no meu percurso enquanto professora e pesquisadora. À medida em que me desafiava a trabalhar com a mesma, TCC, mestrado e doutorado, ampliava meu entendimento e inúmeras aprendizagens eram oportunizadas. A forma de escrever, por meio de metáforas, a percepção do ser pesquisadora, nunca distante e imparcial diante do fenômeno em estudo, os caminhos e ferramentas no processo de constituição e análise do material empírico, sempre se diferenciavam do que alguns, recorrentemente faziam.

O processo de constituição do vir a ser professor carrega consigo as marcas, vivências e experiências que estruturam nossa professoralidade. Neste texto abordarei algumas das experiências que constituíram meu percurso de estudo e trabalho a partir dos pressupostos da ATD. O itinerário dessas experiências, expressos nos portos em que parei, TCC, mestrado e doutorado, sinalizam o ampliar de horizontes, o reabastecimento para viagem, eterna, rumo a novas paisagens. Como constante nesse processo a ATD, companheira nos diferentes percursos entre os portos. No primeiro porto, o TCC, a aprendizagem acerca da função epistêmica da escrita, no porto da dissertação a dimensão estética e sua correlação com o processo de vir a ser professor e, no porto do doutorado, a compreensão da relevância que a ATD teve/tem em meu processo constitutivo de vir a ser professora/pesquisadora e no desafio de compreender esse percurso.

Diante desse cenário, após apresentar brevemente os portos, aprendizagens e compreensões que constituem meu itinerário formativo, adensarei, na sequência, as discussões e percepções acerca da correlação entre a ATD e o processo de desenvolvimento da escrita e autoria do pesquisador. De forma progressiva, sua utilização extrapola as barreiras de sua zona de origem, a Educação em Ciências, e percorre outras 
possibilidades e contextos para aplicação. Ante o exposto, compreendo a relevância de compartilharmos nossas vivências formativas, por meio desse texto socializarei alguns dos entendimentos e compreensões, assim como questionamentos e problematizações, que tem emergido diante do trabalho com a metodologia supracitada. Tenciono, a partir desse exercício de escrita, compreender a potência da ATD no processo de constituição do vir a ser professor/pesquisador e no desenvolvimento de sua autoria. Como material empírico foram analisadas as escritas provenientes dos diários de pesquisa que acompanham a pesquisadora desde sua graduação, além dos próprios textos de pesquisa produzidos no TCC, mestrado e doutorado.

Nesse sentido o texto deste artigo se estrutura a partir de cinco dimensões, que retratam os desafios, aprendizagem e comprensões que tenho experienciado e construído no percurso de constituição do vir a ser professora/pesquisadora mediante os movimentos de apropriação teórico/metodológica da ATD. Destes posso mencionar: demarcações transitórias; itinerário metodológico...entre as opções e inspirações para a tessitura desse texto; compreensões emergentes...um horizonte, várias aprendizagens acerca da ATD e, por último, o ponto final...nunca encerra a compreensão.

\title{
2 Demarcações transitórias...
}

\begin{abstract}
As amarras da embarcação se soltaram sozinhas e eu manejava o timão e as velas como um piloto automático. Sem ter tempo para analisar se era suficiente o que levava comigo, já havia deixado a segurança do porto. Pode ser que essa ambivalência seja necessária para um pensamento que está a cominho da tarefa do pensamento[...] (KNOBBE, 2014, p. 89).
\end{abstract}

Denominar um tópico como "demarcações transitórias" pode parecer incoerente, visto que o termo pode oportunizar entendimentos que destoam entre si. Enquanto o primeiro pode nos levar ao entendimento de fixação e imutabilidade, o segundo oportuniza o oposto, carregando sentidos consigo que refletem o movimento e a reorganização. O que pretendo com esse termo é expressar um sentido de recursividade, de constante complexificação das compreensões teóricas que estruturam meus entendimentos enquanto professora e pesquisadora. Cabe ressaltar que quando utilizo o termo complexificação não me ancoro no entendimento de dificuldade, mas no sentido de intensidade e profundidade. Ou seja, ao complexificar compreensões teóricas tencionase adensá-las no sentido de torná-las mais consistentes, coerentes e compreensíveis.

Porém não podemos estagnar, mesmo sem a certeza do que virá e se o que nos acompanha será suficiente para a viagem, precisamos partir. Como menciona Knobbe 
(2014), na epígrafe deste tópico, precisamos deixar a segurança do porto. E por meio desses enfrentamentos, na viagem, muitas aprendizagens serão construídas, paisagens e horizontes ampliados.

O que pensamos hoje, amanhã já poderá ser diferente. Nós próprios não seremos os mesmos. É como a metáfora, baseada em Heráclito, utilizada no capítulo escrito por Moraes (2006), "ninguém se banha duas vezes no mesmo rio". Ao explicar o objetivo da utilização da metáfora para discutir o conceito de currículo Moraes (2006, p. 40) argumenta:

Com a metáfora heraclitana de que não é possível entrar duas vezes no mesmo rio [...] pretende-se expressar a natureza dialética de todo esse processo. Tanto os currículos em reconstrução como os professores que os reconstroem são permanentemente inacabados em sua própria natureza. $\mathrm{O}$ processo proposto reflete um esforço de os professores se envolverem consiente e autonomamente nesses processos, assumindo-se assim como profissionais da educação num sentido mais pleno.

Por meio da compreensão, expressa pelo autor, podemos transpor a metáfora supracitada para pensar o desenvolvimento da autoria do pesquisador a medida em que se apropria do referencial teórico/metodológico que ancora a ATD. Tanto o pesquisador que se apropria da ATD, quanto a própria metodologia, encontram-se inacabados. A cada encontro, em um exercício de aprender mais acerca de como trabalhar com a ATD, novas possibilidades e entendimentos são construídos e por meio do desenvolvimento da escrita, inerente a essa metodologia, a autoria é constantemente desafiada e alimentada. Não só o rio não é o mesmo, mas nós também não seremos iguais. À medida que nos apropriamos de um referencial teórico/metodológico, nossa compreensão se complexifica, oportunizando um ampliar de horizontes. Nos reabastecemos rumo a novos portos.

Ao discorrerem acerca da dimensão da autoria na ATD, os autores argumentam que a mesma não se configura com uma opção, mas sim como uma exigência. Nas suas palavras:

Operar entre caos e ordem é mergulhar na intensidade dos fenômenos, explorando sua profundidade pelo envolvimento e participação intensa. Implica atingir a não linearidade dos fenômenos, o caótico criativo e a dimensão incontrolável da inovação surpreendente. Atingir a profundidade e a intensidade dos fenômenos exige participação intensa do pesquisador em sua subjetividade e individualidade, processo de criação e imaginação em que a autoria não é uma opção, mas uma exigência (MORAES; GALIAZZI, 2016, p. 244).

Como uma metodologia de análise de informações discursivas vinculada, predominantemente, a pesquisa de natureza qualitativa, a ATD exige, dos que se desafiam a trabalhar com ela, o desenvolvimento do exercício de escrita e da própria autoria. Não 
basta escrever, apenas pontuando uma série de autores que se aproximam do que o pesquisador pretende argumentar, mas sim elaborar um texto que se estruture a partir da análise e posicionamento crítico do autor do texto, de sua autoria. Dimensão expressa pelos autores ao afirmarem que a produção escrita, na perspectiva teórico/metodológica da ATD, é "[...] mais do que estruturar textos a partir das ideias de outros. Requer organizar produções escritas a partir de seus próprios pontos de vista, textos organizados em torno de sua autoria" (MORAES; GALIAZZI, 2016, p. 249).

Nesse cenário, a compreensão da função epistêmica da escrita, nos movimentos inerentes a ATD, fica explícita. Ao tencionar construir zonas de definição da ATD e sua relação com a produção de metatextos, os autores mencionam que a mesma pode ser descrita como um processo de compreensão. Nas suas palavras:

\begin{abstract}
A Análise Textual Discursiva, culminando numa produção de metatextos, pode ser descrita como um processo emergente de compreensão, que se inicia com um movimento de desconstrução em que os textos do corpus são fragmentados e desorganizados, seguindo-se um processo intuitivo auto-organizado de reconstrução, com emergência de novas compreensões que, então, necessitam ser comunicadas e validadas cada vez com maior clareza em forma de produções escritas.
\end{abstract}

Todo o processo de produção escrita, na ATD, materializa-se por meio do metatexto. Muito se questiona acerca do que seria o metatexto e como o mesmo se estrutura. Essa pode ser destacada como uma das questões que mais recebi, sempre que era questionada sobre a metodologia. A característica central do metatexto é a escrita, mas não qualquer escrita, e sim aquela carregada pela autoria do pesquisador. No entanto, antes de compartilhar o entendimento que tenho construído acerca do metatexto, compreendo como relevante revisitar a definição expressa pelos autores. Moraes e Galiazzi (2016, p. 54-55), ao discorrerem acerca do metatexto e sua correlação com a ATD, argumentam:

Todo o processo de Análise Textual Discursiva volta-se à produção do metatexto. A partir da unitarização e categorização constrói-se a estrutura básica do metatexto. Uma vez que construídas as categorias, estabelecem-se pontes entre elas, investigam-se possíveis sequências em que poderiam ser organizadas, sempre no sentido de expressar com maior clareza as intuições e compreensões atingidas. Simultaneamente, o pesquisador pode ir produzindo textos parciais para as diferentes categorias que, gradativamente, poderão ser integrados na estruturação do texto como um todo.

Compreendo, com base no percurso que tenho construído no trabalho com a ATD, que o metatexto se trata de um exercício de tessitura e ampliação de horizontes compreensivos. Quando falo em tessitura, direciono-me ao entendimento de que o metatexto se delinenia como um exercício de escrita em forma de tessitura argumentativa, 
que entrelaça o material empírico, os argumentos teóricos emergentes e os do próprio pesquisador. Por meio desse processo desafiador, criam-se condições de possibilidade para o desenvolvimento da autoria, uma característica de escrita do pesquisador, geralmente carregada por um conjunto de metáforas que ajudam a ele e aos leitores a compreender o processo de ampliação de horizontes, oportunizado pela ATD.

No segundo momento de meu argumento, acerca do metatexto na ATD, menciono o processo de ampliação de horizontes. Compreendo esse movimento como o desafio de entender e perceber o que o fenômeno, foco do estudo, tem a mostrar; que compreensões posso construir, com base no material empírico, teóricos e minhas próprias percepções, e que possibilitarão com que perceba cores e nuances antes não vislumbradas. Trata-se, nesse movimento, do processo de fusão de horizontes, sejam eles os do pesquisador, os do fenômeno em estudo e o dos teóricos utilizados.

Esse entendimento coaduna com as metas da ATD, mencionadas pelos autores, ao argumentarem que a mesma "[...] inserida no movimento da pesquisa qualitativa não pretende testar hipóteses para comprová-las ou refutá-las ao final da pesquisa; a intenção é a compreensão, a reconstrução de conhecimentos existentes sobre os temas investigados" (MORAES; GALIAZZI, 2016, p. 33).

A partir do processo de desenvolvimento da autoria, o pesquisador envolve-se em um processo de formação, que por vezes é imperceptível. Ao apropriar-se dos princípios e fundamentos da ATD, o pesquisador é provocado e desafiado constantemente a repensar-se, por meio desse processo oportuniza-se um contexto formativo de vir a ser. Moraes e Galiazzi (2016) argumentam acerca dessa nuance e mencionam a relevância da autoria, que consiste das marcas do pesquisador, sempre articuladas a outras vozes, sejam elas empíricas ou teóricas. Nas suas palavras:

\footnotetext{
Assim, uma perspectiva hermenêutica e reconstrutiva da ATD exige a presença de autoria do pesquisador. As aprendizagens e novas compreensões construídas devem trazer necessariamente a marca do pesquisador, a manifestação de seus pontos de vista, as novas compreensões apresentadas a partir de sua própria perspectiva, ainda que sempre sustentadas em outras vozes, quer de sujeitos empíricos, quer de teóricos com os quais foram realizados diálogos (MORAES; GALIAZZI, 2016, p. 247).
}

A aproximação entre o sujeito e o objeto, perspectiva a ser assumida com o desenvolvimento de uma análise a partir da ATD, delineia-se como um elemento estruturante no desafio do desenvolvimento da autoria. Por meio do movimento inerente à interpretação do fenômeno em estudo e da tarefa de compartilhar suas percepções com 
futuros leitores, o pesquisador é provocado, no exercício de escrita, a compreender-se como sujeito inconcluso, como mencionam os autores:

Numa decisiva aproximação sujeito-objeto, a ATD requer um pesquisador que assume suas interpretações e pontos de vista, com autorias emergentes no processo das análises a partir de uma intensa impregnação com os fenômenos, exigindo, ao mesmo tempo, conviver com dúvidas e inseguranças ao longo de todo processo. $\mathrm{O}$ conhecimento produzido constitui-se em autoconhecimento, com autorias assumidas durante todo o processo (MORAES; GALIAZZI, 2016, p. 248).

Esse processo de aproximação entre sujeito e objeto e o desafio de migrar da escrita descritiva para a interpretativa criam condições de possibilidades para a emergência do novo, no processo de interpretação. Para os autores "somente um envolvimento intenso e comprometido cria as condições de emergência do novo, possibilitando a autoria e produção de autoconhecimento" (MORAES; GALIAZZI, 2016, p. 251).

Ancorados pelas compreensões inerentes aos princípios teórico/metodológicos da ATD, os autores destacam alguns elementos constituintes dos movimentos inerentes a mesma, desses mencionam: a ruptura, a reconstrução, a interpretação, a autoria e o movimentar-se na linguagem. Nas palavras dos autores, o trabalho com a ATD demanda:

- exigência de rupturas com pressupostos epistemológicos, ontológicos e metodológicos associados ao paradigma dominante de ciência, com movimentos em direção a novos paradigmas.

- perceber o processo de análise como movimento permanente de reconstrução de compreensões já anteriormente constituídas a partir da interação como outros pontos de vista;

- entender o processo de análise exigindo a presença constante do pesquisador em sua capacidade interpretativa e em suas autorias, concebendo o conhecimento produzido como autoconhecimento do pesquisador;

- os movimentos da ATD vão da semântica à hermenêutica, com intenso envolvimento na linguagem numa perspectiva de discursos sociais, exigindo ao pesquisador inserir-se em círculos hermenêuticos capazes de lhe possibilitarem compreensões cada vez mais elaboradas e válidas, seguidamente criando espaços para a metáfora como modo de sua expressão (MORAES; GALIAZZI, 2016, p. 256).

Diante dessa conjectura, pode-se argumentar acerca da relevância do exercício de escrita inerente a ATD, mediante seu objetivo a produção de metatextos, no processo de desenvolvimento da autoria e na formação do pesquisador. Sendo o metatexto estruturado e resultado no/do percurso de análise decorrente do processo de unitarização e categorização. Nesse sentido, os autores argumentam que:

O objetivo da Análise Textual Discursiva é a produção de metatextos baseados nos textos do corpus. Esses metatextos, descritivos e interpretativos, mesmo sendo organizados a partir das unidades de significado e das categorias, não se constituem em simples montagens. Resultam de processos intuitivos e autoorganizados. A compreensão emerge, tal como em sistemas complexos, revelando-se muito mais do que uma soma de categorias. Dentro dessa 
perspectiva, um metatexto, mais do que apresentar as categorias construídas na análise, deve constituir-se a partir de algo importante que o pesquisador tem a dizer sobre o fenômeno que investigou, um argumento aglutinador construído a partir da impregnação com o fenômeno e que representa o elemento central da criação do pesquisador. Todo texto necessita ter algo importante a dizer e defender e deveria expressá-lo com o máximo de clareza e rigor (MORAES; GALIAZZI, 2016, p.62).

Nesse ínterim, a ATD pode ser compreendida como um referencial teórico/metodológico potente, tanto no que se refere à análise de informações discursivas quanto a outras dimensões, como o desenvolvimento da autoria do pesquisador e de compreensões inerentes ao fazer pesquisa. Ela ensina, ao pesquisador, como escrever com autoria e, em conjunto a isso, oportuniza um movimento de compreensão do material empírico da investigação, e de forma paralela possibilita um ampliar de horizontes acerca dos saberes e fazeres da pesquisa de natureza qualitativa e do vir a ser professor/pesquisador.

\title{
3 Itinerário metodológico...Entre as opções e inspirações para a tessitura desse texto
}

\begin{abstract}
Tomo a narrativa como uma inspiração. Cada ideia posta no papel é uma zona de passagem na qual chegam, para em seguida partir novamente, os estados do pensamento. Escolher, esticar, deslizar constristar vivências e ideias nas palavras são formas de manter o pensamento em ação. Nesse trajeto em espiral, é necessário, por vezes, rir e gargalhar, evitando os riscos de intoxicação de sentido (KNOBBE, 2014, p. 27-28).
\end{abstract}

O desenho de um texto perpassa as opções e inspirações que delineiam o itinerário metodológico. Diante dessa conjuntura, como inspiração e aportes teórico/metodológicos para construção desse texto, que tenciona compreender a correlação da ATD com o desenvolvimento da autoria do pesquisador, buscou-se ancoragem nos argumentos tecidos por autores como Knobbe (2014) e Moraes e Galiazzi (2016).

Como tenho argumentado ao longo deste texto, compreendo que a ATD se delineia como uma válida ferramenta nos processos inerentes à escrita e à compreensão de diferentes temáticas. Para além da sua utilização como referencial de análise de informações discursivas, ou seja, do material empírico nas pesquisas, compreendo-a como um referencial de investigação, como um norte acerca dos princípios da investigação de natureza qualitativa e de como estruturar um texto.

Nesse movimento, também me ancoro nas reflexões, problematizações e compreensões tecidas por Knobbe (2014). A autora, no intento de compreender o que seria a compreensão, debruça-se na escrita de um texto, de caráter narrativo, ancorada por 
referenciais teóricos de distintas áreas. Sua escrita assume a perspectiva de um diário, estabelece um diálogo provocativo com os leitores, pontuando suas vivências, experiências e entendimentos de autores, dentre eles do campo da literatura.

Ancorada por essas inspirações, construo este texto, com ênfase na investigação de natureza qualitativa, e que tenciona, por meio da análise dos diários e dos textos de investigação que tenho produzido ao longo do meu percurso formativo enquanto professora e pesquisadora no TCC, mestrado e doutorado, via ATD, compreender a relação dessa metodologia com o desenvolvimento da autoria do pesquisador.

Por meio do processo de análise dos diários e textos, via ATD, emergiram dezessete unidades de significado, que foram analisadas, diante da temática e possibilitaram a emergência de quatro categorias iniciais, duas categorias intermediárias e uma categoria final. A categoria final foi intitulada de "Um horizonte, várias aprendizagens acerca da ATD”. O processo de categorização pode ser acompanhado no Quadro 1, na sequência:

Quadro 1: Processo de categorização

\begin{tabular}{|c|c|c|}
\hline Cat. Inicial & Cat. Intermediária & Cat. Final \\
\hline $\begin{array}{l}\text { A - A complexificação dos modos de } \\
\text { percorrer os caminhos metodológicos da } \\
\text { ATD foi se complexificando por meio das } \\
\text { experiências }(9)^{2}\end{array}$ & \multirow{2}{*}{$\begin{array}{l}\qquad[\mathrm{A}+\mathrm{C}]= \\
\qquad(9+3)=12 \\
\text { A compreensão e entendimentos } \\
\text { acerca dos movimentos da ATD se } \\
\text { complexificam na medida em que as } \\
\text { experiências e aprendizagens são } \\
\text { ampliadas }\end{array}$} & \multirow{4}{*}{$\begin{array}{l}\qquad[\mathrm{A}+\mathrm{C}]+[\mathrm{B}+\mathrm{D}]= \\
\qquad[12]+[5]=17 \\
\text { Um horizonte, várias } \\
\text { aprendizagens acerca } \\
\text { da ATD }\end{array}$} \\
\hline $\begin{array}{l}\text { C - Os desafios oportunizam aprendizagens } \\
\text { e percepções ( } 3 \text { ) }\end{array}$ & & \\
\hline $\begin{array}{l}\text { B - As sensações afloram no trabalho a } \\
\text { partir da ATD, nesse processo desenvolver } \\
\text { a sensibilidade é uma aprendizagem (2) }\end{array}$ & \multirow[b]{2}{*}{$\begin{array}{l}\text { A sensibilidade e a escrita se } \\
\text { aproximam em termos de } \\
\text { aprendizagem na ATD, por meio } \\
\text { desse movimento } \\
\text { desenvolvimento de metáforas } \\
\text { aflora }\end{array}$} & \\
\hline $\begin{array}{l}\mathrm{D} \text { - Aprender com a ATD envolve a } \\
\text { apropriação de linguagens como a metáfora } \\
\text { (3) }\end{array}$ & & \\
\hline
\end{tabular}

Fonte: Desenvolvido pela autora

No próximo tópico o metatexto, produzido a partir da análise dos diários e textos, abordará algumas compreensões acerca da realação entre o processo de apropriação teórico/metodológica da ATD e o desenvolvimento da autoria do pesquisador, além de seu percurso de vir a ser professor/pesquisador.

\footnotetext{
${ }^{2} \mathrm{O}$ número entre parênteses representa o quantitativo de unidades de significado que pertencem a categoria.
} 


\title{
4 Compreensões emergentes...Um horizonte, várias aprendizagens acerca da ATD
}

\begin{abstract}
A compreensão pertence à esfera da sensibilidade e da ação porque o pensamento também cansa, de acordo com o poeta. Tentar compreender algo apenas pelo viés da razão conduz a um estado de inércia, à indiferença. Por outro lado, não cansamos de tentar compreender porque é dessa forma que, ao esgotarmos os próprios pensamentos, temos necessidade de sentir o influxo das opiniões alheias, mesmo que não sigamos o seu impulso (KNOBBE, 2014, p. 71).
\end{abstract}

Meu contato com a ATD ocorreu por meio das aulas de Monografia que tínhamos semanalmente, na universidade em que me formei. O curso de Licenciatura em Química ofertava um componente curricular com foco na discussão do TCC. Nesse espaço aprendíamos, de forma coletiva, os meandros do fazer pesquisa em Educação Química. Constituíram nossas discussões as distintas etapas que perpassam o fazer pesquisa, desde a elaboração de um título, resumo, fundamentação teórica, metodologia, conclusões, referenciais, enfim a estrutura mínima exigida na redação de pesquisas acadêmicas. Mas, além disso, aprendemos acerca da potencialidade de aprender com o outro, da função epistêmica da escrita, sobre como organizar fichamentos, como delimitar uma temática, em compreender a importância do olhar do outro no processo de aperfeiçoamento da escrita.

Obviamente que em algumas das aulas acabamos discutindo os princípios da ATD, e mais do que isso, aprendemos sobre com os autores do livro. Tivemos a honra de ter como docentes no componente curricular de Monografia o professor Roque Moraes e a professora Maria do Carmo Galiazzi. Naquele momento, muitos de nós não tínhamos a compreensão do quanto aquele contexto oportunizaria aprendizagens ímpares para nossa constituição enquanto professores e pesquisadores. Atualmente, percebo nitidamente a influência que aquele contexto teve/tem em minha formação, não só no processo de compreensão da ATD, mas na sedimentação dos alicerces que me constituem como professora/pesquisadora.

Diante desse contexto, é impossível compreender o processo de desenvolvimento da autoria e da própria ATD centrada, apenas, nos elementos da razão. Os sentimentos que afloram ao revisitar esses cenários formativos, os portos que constituem meu percurso de professora/pesquisadora, fazem-se presentes de maneira constante nesse exercício de compreensão. Como argumenta Knobbe (2014, p. 71), logo no começo desse tópico "a compreensão pertence a esfera da sensibilidade e da ação [...]”. 
Ante o exposto, o metatexto, tecido a partir das unidades de significado provenientes dos diários de pesquisa, produzidos no TCC, mestrado e doutorado, e os textos de pesquisa, referentes a esses espaços, em conjunto das compreensões da autora e de teóricos emergentes, tenciona compartilhar com os leitores um movimento de compreensão do processo de desenvolvimento da autoria do pesquisador, via ATD, assim como alguns dos pressupostos dessa metodologia. De forma recorrente, emergiram como temáticas questões correlatas às aprendizagens e experiências oportunizadas via ATD, assim como a relação entre a escrita e a sensibilidade no desafio de desenvolver um exercício de escrita e autoria metafórica.

Em diversas unidades de significado emerge a compreensão de que a complexificação dos modos de percorrer os caminhos metodológicos da ATD vai se ampliando por meio das experiências. Em uma das escritas, provenientes do diário de pesquisa da Monografia, fica explícito um primeiro movimento de apropriação dos movimentos que constituem a ATD e das opções selecionadas para realização dos mesmos. Na unidade de significado é mencionado o fato de que os portfólios, selecionados para pesquisa da Monografia, serão análisados via ATD e trechos desses serão transcritos para, posteriormente, serem aproximados e estudados diante de teóricos. Percepções que podem ser observadas na sequência:

\begin{abstract}
Após encontros e diálogos com meus orientadores, decidi conjuntamente com estes analisar os Portfólios através da análise textual discursiva (ATD). Onde estes Portfólios serão lidos, analisados e após trechos ou partes importantes nestes serão transcritos. Mediante a estas análises, alguns tópicos que se demonstram comuns nas escritas serão analisados e mais profundamente estudados através de referenciais teóricos adequados a estes [DP.M.1(01/06/2010) $]^{3}$.
\end{abstract}

No processo de unitarização dos portfólios, a pesquisadora relata compreender a pertinência das etapas inerentes a esse momento, ou seja, leitura, pré-análise e transcrição. Nesse exercício, a relevância da fundamentação teórica, como um movimento de complexificação do exercício de análise, fica explícita na unidade supracitada. Outra nuance, que pode ser destacada, refere-se à opção por utilização de teóricos emergentes. Nesse cenário a fundamentação teórica é selecionada após a análise do material empírico,

\footnotetext{
${ }^{3} \mathrm{O}$ código identifica o espaço a que a escrita pertence. O DP se refere a diário de pesquisa, após o ponto a letra se refere a qual diário, $\mathrm{M}$ se relaciona a Monografia, D dissertação e $\mathrm{T}$ a tese. Na sequência, o ponto se refere ao número da unidade de significado, vinculada ao diário e após a data da escrita. O código [DP.M.1(01/06/2010)] se refere a primeira unidade de significado do diário da Monografia, redigida em junho de 2010.
} 
diante de um processo de categorias emergentes. Acerca dessa nuance, Moraes e Galiazzi (2016, p. 41) argumentam:

As unidades de análise são sempre identificadas em função de um sentido pertinente aos propósitos da pesquisa. Podem ser definidas em função de critérios pragmáticos ou semânticos. Num outro sentido, sua definição pode partir tanto de categorias definidas "a priori", como de categorias emergentes.

No processo de análise, mencionado na unidade de significado [DP.M.1(01/06/2010)] a pesquisadora, em conjunto de seus orientadores, optou pelo percurso semântico de análise do material empírico. Analisando o texto de forma a compreender que pistas o material empírico oportunizaria, considerando sua questão de pesquisa, mas aberta ao que poderia emergir em termos de temáticas correlatas ao fenômeno. Essa opção carrega consigo o desafio de categorias emergentes, não delineadas previamente pelo pesquisador, e em conjunto aportes teóricos que também emergirão e demandarão a busca do pesquisador por vozes que potencializem e o ajudem no processo de compreensão.

No texto de pesquisa do TCC, a pesquisadora relata que no proceso de análise, após organizar os dados e categorias diante de temáticas constantes, foram selecionados teóricos para auxiliar no processo de compreensão. Nas suas palavras:

A medida que estas etapas eram realizadas, com a finalidade de organizar os
dados obtidos se categorizou alguns dos temas que se demonstraram constantes
nas análises dos textos. Criando três categorias principais, para que fossem
então melhor compreendidas no processo de pesquisa. Buscando assim, além
de uma teorização acerca do tema, possibilitar um estudo mais profundo sobre
este a fim de compreendê-los mais profundamente [T.M.2(2010) ${ }^{4}$.

Assumir a perspectiva de trabalho a partir de categorias e teóricos emergentes oportuniza ao pesquisador um movimento de investigação de natureza hermenêutica, tencionando compreender o fenômeno, foco de estudo, a partir de como ele se mostra. Acerca dessa nuance, Moraes e Galiazzi (2016, p. 181) pontuam que:

A partir de seu viés hermenêutico ela se aproxima de forma decisiva das teorias emergentes, movimentos de teorização que se originam nas manifestações discursivas dos sujeitos das pesquisas. Novamente, mais do que movimentos a favor ou contra a corrente do rio, representam mergulhos em profundidade, movimentos discursivos que constroem e reconstroem as realidades investigadas.

\footnotetext{
${ }^{4} \mathrm{O}$ segundo sistema de codificação se refere a identificação das unidades de significado provenientes dos textos de pesquisa a nível de TCC, mestrado e doutorado. O T se rerere a texto de pesquisa, após o ponto a letra se refere a qual nível, $\mathrm{M}$ se refere a Monografia, D dissertação e T a tese. Na sequência, o ponto, e o numeral se refere ao número da unidade de significado, vinculada ao texto e após a data da escrita. O código [T.M.2(2010)] se refere a segunda unidade de significado do texto de pesquisa da Monografia, redigida em 2010.
} 
Muito se questiona se a opção por categorias/teorias emergentes ou a priori seria uma via de análise para determinar se uma investigação se ancorou ou não nos pressupostos teórico/metodológicos da ATD. No entanto, vale ressaltar, como base na compreensão expressa pelos autores no trecho acima que, mais do que limitar a ATD a uma ou outra opção, precisamos compreender os objetivos e argumentos construídos. Como mencionam, "mais do que ir contra ou a favor da corrente do rio", se vamos analisar nosso mateiral empírico com teorias pré-definidas ou se estaremos abertos ao que emerge, vamos nos desafiar a compreender o fenômeno, foco do estudo, em sua profundidade e complexidade. Vamos ir ao fundo do rio, antes de ir a favor ou contra a correnteza.

Apesar da ATD se aproximar mais da perspectiva inerente às categorias e teorias emergentes, esse não pode ser delineado como fator de classificação para o enquadramento ou não de uma investigação como coerente aos princípios da ATD. Muitos desafios são propostos ao pesquisador, quanto este se desafia a trabalhar com a ATD, um deles se refere ao desenvolvimento da autoria e da passagem de uma escrita descritiva para interpretativa. Ao abordarem essa nuance Moraes e Galiazzi (2016, p. 57) discorrem:

Entende-se a descrição como esforço de exposição de sentidos e significados em sua aproximação mais direta com os textos analisados. Descrever, nesse sentido, constitui-se num movimento de produção textual mais próximo do empírico, sem envolver um exercício interpretativo mais aprofundado. Desse modo, a descrição significa uma exposição de ideias de uma perspectiva próxima de uma leitura imediata, mesmo que cuidadosa e detalhada. $\mathrm{Na}$ medida em que o pesquisador se afasta dessa realidade mais imediata do texto, entretanto, está se envolvendo gradativamente mais num exercício interpretativo.

$\mathrm{Na}$ escrita, vinculada ao diário de pesquisa do mestrado, é relatado o movimento de análise mais complexo, quando comparado ao do TCC. O mesmo se estruturou por meio da imersão no material empírico diante de algumas etapas, destas pode-se observar: a transcrição, a elaboração de palavras-chave e títulos. Na sequência, por aproximação de temáticas, diante da semelhança, emergiram as categorias. Esses movimentos podem ser observados na unidade de significado na sequência:

Diante destes pressupostos a análise das escritas dos diários teve como etapa
inicial a realização de uma leitura geral das escritas, para que com isso uma
imersão acerca do que está sendo abordado nos diários, na sequência partiu-se
para a transcrição e análise das mesmas. No momento de análise para cada
unidade de significado, que se constituía por uma escrita no diário, foram
elaboradas palavras-chaves e na sequência um título, nesse movimento
buscou-se maior compreensão acerca do que a escrita abordava. Após, foram
observadas as temáticas constantes ao longo das unidades de significado e
assim alcançaram-se as categorias iniciais. Diante das categorias iniciais
partiu-se para um movimento de atribuir palavras-chaves e um título para cada
categoria inicial, a partir destes novos títulos chegasse novamente via 
agrupamento por semelhanças de sentidos as categorias intermediárias. Seguindo o mesmo movimento diante das categorias intermediárias, criaramse argumentos para cada uma das categorias, e assim chegou-se as categorias finais [T.D.1(2014)].

A apropriação das nuances e momentos que constituem a ATD se desenvolve no desafiar-se em trabalhar com a mesma. Acerca dos movimentos, inerentes à unitarização e categorização, Moraes (1999) apresenta três momentos a serem considerados, destes menciona: fragmentação dos textos e codificação de cada unidade; reescrita de cada unidade, na intencionalidade de que possa assumir um significado; atribuição de nome ou título para cada unidade.

No texto de pesquisa, vinculado ao doutorado, fica mais explícito como pode ocorrer o processo de análise, via títulos, diante da aproxiação e considerando os códigos que estruturaram a análise. $\mathrm{O}$ processo pode ser observado na unidade de significado a seguir:

Por meio da análise dos títulos, busca-se realizar um primeiro exercício de
aproximação, ou seja, analisando os títulos tenciona-se perceber discussões
semelhantes. Nesse movimento de aproximação começam a emergir as
categorias iniciais da pesquisa. Sendo estas representadas por meio de um
código, em nosso caso por letras do alfabeto como A, B, C e assim por diante.
Para cada categoria inicial teremos um conjunto de unidades de significado, no
exercício de buscar nominar essas categorias iniciais, busca-se selecionar
palavras-chave, por meio dos enunciados, os títulos, das unidades de
significado que a compõem e por sequência um argumento parcial para cada
categoria inicial. Esse argumento objetiva sintetizar os sentidos expressos
nessa categoria inicial e por decorrência nas unidades de significado que a
compõe [T.T.3(2019)].

Com a intencionalidade de organizar o material empírico e potencializar os movimentos de análise, a pesquisadora menciona a utilização de ferramentas, como o Word e o Excel. Dimensão explicitada na unidade abaixo:

Cabe ressaltar que o processo de análise se orientou por categorias emergentes e foi desenvolvido manualmente, tendo como recursos auxiliares o Word e o Excel. Sendo o Word utilizado no processo de transcrição das informações empíricas e o Excel no processo de categorização, por meio de recursos como o de classificação. Acerca do processo de análise das unidades de significado, compreendemos como pertinente elucidar que a interpretação e compreensão do texto ocorreu a partir do que se mostrava como explícito e implícito. Ancorando este processo por meio das vivências da pesquisadora junto aos licenciandos e das reflexões desenvolvidas no diário de pesquisa [T.T.6(2019)].

Sobre o terceiro movimento de análise, que se constitui pelo exercício de comunicação das compreensões via metatexto, a escrita do texto de pesquisa, vinculada ao doutorado, expressa:

O terceiro movimento da ATD se configura como um exercício de comunicação das compreensões construídas e emergentes do processo de unitarização e análise, oportunizando a construção do metatexto. Sendo este 
composto por um processo de ancoragem das unidades de significados, das teorias emergentes da análise e das compreensões construídas pelo pesquisador [T.T.5(2019)].

Todo processo de análise, inerente a ATD, culmina na elaboração do metatexo. Quando os movimentos anteriores, unitarização e categorização, são realizados rumo a uma progressiva interpretação das unidades de significado, via elaboração de palavraschave, títulos e argumentos, a escrita do metatexto se torna menos árdua e pré-organizada.

Acerca dos objetivos inerentes a produção do metatexto Moraes e Galiazzi (2016, p. 53) argumentam:

Se no primeiro momento da análise textual se processa uma separação, isolamento e fragmentação de unidades de significado, na categorização, o segundo momento da análise, o trabalho dá-se no sentido inverso: estabelecer relações, reunir semelhantes, construir categorias. O primeiro é um movimento de desorganização e desmontagem, uma análise propriamente dita; o segundo é de produção de uma ordem, uma compreensão, uma síntese. A pretensão não é o retorno aos textos originais, mas a construção de um novo texto, um metatexto que tem sua origem nos textos originais, expressando a compreensão do pesquisador sobre os significados e sentidos construídos a partir deles.

A estruturação do metatexto pode ser organizada a partir das categorias finais, sendo assim, para cada categoria final, elabora-se um metatexto. Por decorrência, o metatexto pode se estruturar diante das categorias intermediárias que o compõem. Diante desse cenário, o metatexto poderá se constituir, a partir de subtópicos, considerando cada categoria intermediária um subtópico, uma dimensão. Na sequência, para cada uma dessas dimensões, ou seja, as categorias intermediárias podem ser inseridas as categorias iniciais que as compõem e por sequência as unidades de significado que se vinculam as mesmas.

Ao final de cada categoria inicial, é pertinente alocar um argumento que contemple o cerne das discussões abordadas na mesma. O mesmo movimento deve ser realizado ao final, na conclusão do subtópico/dimensão da categoria final. Após apresentar todos os conjuntos, de categorias intermediárias e as iniciais que as compõem, é adequado inserir um argumento aglutinador, na forma de síntese argumentativa do que é contemplado no metatexto.

Uma proposta de organização e estruturação do metatexto, construída a partir do processo de análise realizado nesse artigo, pode ser observada na sequência. 
Figura 1: Estrutura do metatexto

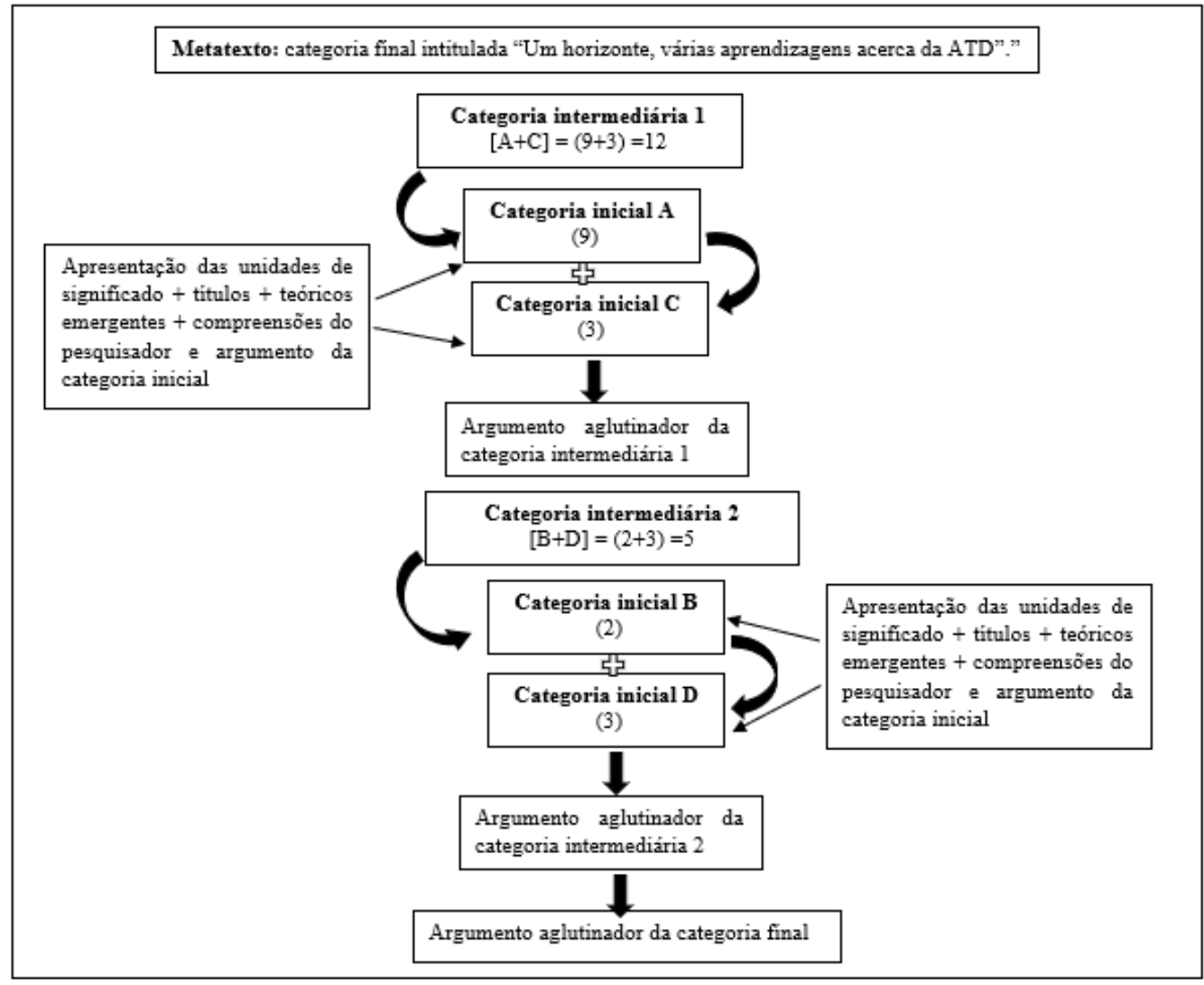

Fonte: Desenvolvida pela autora

À medida que o pesquisador, durante o processo de unitarização e categorização, desafia-se progressivamente a interpretar as unidades de significado que seleciona e aproxima, já delineia a estrutura do metatexto. Nesse cenário, quando conclui os movimentos de categorização e migra para a tessitura do metatexto, pode perceber que não partirá de uma "folha em branco", sua escrita já se estruturou na análise. Diante dessa percepção, tenho compreendido que mais do que uma metodologia de análise de informações discursivas, a ATD ensina o pesquisador a escrever.

Ancorada por esse entendimento, uma proposta de organização e estruturação do metatexto, considerando os movimentos de análise realizados nesse texto, foi estruturada e pode ser observada na Figura 1. Nesse ínterim, ao terminar a categorização, o pesquisador pode ir delineando a estrutura do metatexto inserindo, inicialmente, as categorias intermediárias. Após pode incorporar, no espaço destinado às categorias intermediárias, as respectivas categorias iniciais que a compõem. Na sequência, pode selecionar as unidades de significado mais representativas para cada categoria inicial. No movimento de inserir cada unidade de significado, pode incorporar os títulos construídos para cada unidade. E nesse processo, o texto, o metatexto, organiza-se e quando o 
pesquisador menos espera, já não está mais com a tela branca do computador o assombrando.

O bloqueio com a escrita pode ser mencionado como um dos fatores que dificultam e tornam árduo o processo de desenvolvimento de uma investigação. Marques (2008, p. 31) menciona que "[...] são muitos os casos de pessoas que diante da brancura da folha se acham como que paralisadas, quando não tomadas de pânico”. Diante desse cenário, o exercício de interpretação, já delineado na unitarização e categorização na ATD, provoca o pesquisador a escrever de forma interpretativa e progressiva via elaboração de palavras-chave, títulos e argumentos. E antes mesmo de se deparar com a tela em branco do computador, já tem um esboço do seu texto de análise, nesse caso o metatexto.

As experiências com a ATD oportunizam inúmeros desafios ao pesquisador, que por consequência constrói diversas aprendizagens e percepções. Dentre as aprendizagens e percepções, construídas acerca da ATD e relatadas pela pesquisadora em seus diários de pesquisa, pode-se destacar a participação em um componente curricular que tinha como foco principal discutir os conceitos teórico/metodológicos da mesma. Como pode ser observado na unidade de significado na sequência:

Participar da disciplina de ATD está sendo muito importante para minha pesquisa, penso que o maior encantamento que percebo nessa metodologia é o fato de que cada um acaba a percebendo e a compreendendo a sua maneira. Obviamente que temos alguns elementos que devem ser seguidos, mas a forma como conduzimos este processo acaba sendo interna e individual de cada um [DP.D.1(25/11/2011)].

Experienciar o espaço de um componente curricular com foco na ATD foi muito importante para o processo constitutivo da pesquisadora, aumentou o encantamento e percepções acerca da mesma. Compartilhar espaços com outras pessoas, que tencionam discutir e aprender sobre determinada temática, oportuniza aprendizagens ímpares. É nesse contexto que os horizontes podem ser ampliados, paradas estratégicas em portos de reabastecimento, que alimentam o desejo de seguir em viagem rumo a novos desafios e paisagens. Como argumenta Moraes (1991, p. 6) “[...] o verdadeiro crescimento individual só é possível na relação dialética com os outros".

Em conjunto do encantamento emergem desafios, como no processo de unitarização. Já no início do processo de análise, na unitarização, o pesquisador precisa tomar decisões importantes, como de que forma realizar a fragmentação do texto. Essa nuance é contemplada na escrita do texto de pesquisa, que constituí a unidade de significado na sequência: 
Nesse sentido, no primeiro momento da análise, ou seja, no processo de unitarização, o pesquisador tem como desafio tomar algumas decisões importantes. A partir do material empírico precisa selecionar os trechos que parecem pertinentes ao contexto e foco do fenômeno investigado, esses trechos configuram-se como as unidades de significado. Após essa seleção deve desenvolver um código para que possa retornar com certa facilidade ao material original, caso esse movimento se configure como necessário. $\mathrm{Na}$ sequência, elaboram-se palavras-chave, que representem o sentido expresso no texto que compõe esta unidade. Por meio das palavras-chave, e apenas observando as mesmas, elabora-se um título. Sendo este título uma espécie de enunciado, que visa representar a discussão da unidade de significado [T.T.2(2019)].

Ao discorrerem sobre o movimento de fragmentação dos textos, Moraes e Galiazzi (2016, p. 40) argumentam:

\begin{abstract}
A desconstrução e a unitarização do corpus consistem num processo de desmontagem ou desintegração dos textos, destacando seus elementos constituintes. Significa colocar o foco nos detalhes e nas partes componentes dos textos, um processo de decomposição requerido por qualquer análise. Com essa fragmentação ou desconstrução pretende-se conseguir perceber os sentidos dos textos em diferentes limites de seus pormenores, ainda que se saiba que um limite final e absoluto nunca é atingido. É o próprio pesquisador quem decide em que medida fragmentará seus textos, podendo daí resultarem unidades de análise de maior ou menor amplitude.
\end{abstract}

Delinear a amplitude de fragmentação das unidades de significado, diante do material empírico, precinde do movimento de avaliação de diferentes nuances como: os objetivos, pressupostos teórico/metodológicos, ferramentas utilizadas na constituição do material empírico, características dos sujeitos/colaboradores de pesquisa, gênero discursivo utilizado, entre outros. No percurso que tenho construído no trabalho com a ATD, deparei-me com diferentes situações de investigação, que por decorrência me desafiaram a tomar distintas decisões.

No TCC, por exemplo, trabalhei com portfólios, apenas quatro, mas constituídos por um conjunto significativo de escritas, que se vinculavam às experiências dos licenciandos ao longo de três Estágios Curriculares de Ensino. Nesse cenário, a opção foi fragmentar as escritas dos portfólios, ou seja, cada escrita, que se constituía por reflexões acerca das vivências nos estágios, foi fragmentada diante do olhar da pesquisadora. Já no mestrado, a opção foi não fragmentar as escritas, provenientes de diários de pesquisa produzidos por dezessete licenciandos no decorrer da elaboração de seus TCC. Cada diário continha um média de trinta escritas, que relatavam as aprendizagens, desafios, encantamentos e desencantos inerentes ao fazer pesquisa. Já no doutorado, a opção voltou a ideia de fragmentação do material empírico, ou seja, os portfólios, planos de aula, sequências didáticas e diário de pesquisa tiveram suas escritas fragmentadas. 
Diante do exposto, pode-se observar que fragmentar em maior ou menor intensidade o material empírico demanda um conjunto de análises e avaliação do pesquisador. O tempo para realização da investigação, a quantidade de material empírico e a própria característica das escritas demandam um tratamento específico. No TCC, diante do tempo curto, pouca experiência da pesquisadora entre outras questões, optouse por fragmentar as escritas, subdividindo-as em diversas unidades de significado. Já no mestrado, o desafio foi não fragmentar as escritas dos diários de pesquisa, considerando assim cada escrita como uma unidade de significado. No doutorado, diante da quantidade de material empírico, seis portfólios, seis planos de aula, seis sequências didáticas e um diário de pesquisa a opção se voltou novamente para fragmentação em maior intensidade.

Porém, o pesquisador precisa considerar ainda a que nível a fragmentação vai atingir. Por exemplo, tanto no TCC quanto no doutorado, apesar de assumir um maior nível de fragmetação, quando comparado ao mestrado, as unidades de significado se extendiam a pelos menos um páragrafo. Fragmentar demais o texto, em frases isoladas, ou mesmo em trechos muito restritos, pode limitar a interpretação do fenômeno, foco da investigação.

Do processo de interpretação e aproximação das unidades de significado emerge a categorização. É na categorização que a elaboração de argumentos aglutinadores se delineia como um movimento desafiador e potente na passagem de uma escrita descritiva para a interpretativa. A tessitura dos argumentos aglutinadores precinde de abstração da unidade de significado em sua forma literal, é pertinente que o pesquisador construa os mesmos observando os títulos, em forma de enunciados, construídos para cada conjunto de categorias.

Para Moraes e Galizzi (2016, p. 51-52) o argumento aglutinador estrutura-se pela compreensão de que:

\begin{abstract}
Nesse movimento, o pesquisador, a partir dos argumentos parciais de cada categoria, exercita a explicitação de um argumento aglutinador do todo. Este é então empregado para costurar as diferentes categorias entre si, na expressão da compreensão do todo. Este processo é por natureza recursivo, exigindo crítica permanente dos produtos parciais no sentido de uma explicitação cada vez mais completa e rigorosa de significados construídos e da compreensão atingida.
\end{abstract}

A intensidade, na elaboração e tessitura dos argumentos parciais e aglutinadores, varia também diante das características inerentes ao material empírico analisado. Nesse sentido, quando uma investigação se constituí por uma quantidade maior de unidades de significado, provavelmente a demanda por um exercício, progressivo, de elaboração de 
argumentos parciais será maior quando comparado a pesquisas com material empírico em menor escala. Cabe ressaltar que não estou, nesse momento, argumentando que a qualidade de uma pesquisa se remete a quantidade de informações empíricas selecionadas. Os movimentos de análise é que tornarão os argumentos mais, ou menos, justificados e validados. A intencionalidade dessa reflexão gira em torno, apenas, de nuances a serem consideradas no processo de unitarização, categorização e construção de argumentos diante da natureza do material empírico.

Acerca dos movimentos de análise, que oportunizaram a construção de um argumento aglutinador, a unidade de significado na sequência expressa a compreensão de que:

\begin{abstract}
Nossa proposta de análise se estrutura a partir da seguinte organização: cada conjunto de materiais empíricos, selecionados por componente curricular, compõem um movimento de análise. Após realizar os três movimentos de análise, realizamos um exercício de aglutinação dos argumentos e compreensões construídas nos movimentos anteriores. Esse exercício de aglutinação compõe o quarto movimento de análise. A partir da aproximação das compreensões emergentes do processo de análise, no quarto movimento, tecemos um argumento, que deve se constituir pela potencialidade de aglutinar as pistas acerca do processo de constituição do ser professor de Química [T.T.1(2019)].
\end{abstract}

Ante o exposto, na pesquisa relatada na unidade, diante da quantidade de material empírico, optou-se em organizar a análise por meio de quatro movimentos, que por decorrência se organizaram em três argumentos parciais que foram aglutinados em um argumento final, que compôs o quarto momento de análise. A complexidade do estudo demandou a estruturação de movimentos de análise diferentes que tencionavam se complementar no objetivo de compreender o processo constitutivo de vir a ser professor de Química. Foram acompanhadas as ações realizadas em três componentes curriculares, sendo assim para cada componente se estruturou um movimento de análise, composto por um conjunto de materiais empíricos e que culminou na elaboração de um metatexto de análise. Em cada metatexto de análise, ao final, foi apresentado um argumento parcial. No quarto movimento de análise apresentou-se o argumento aglutinador que tencionou elaborar uma tessitura que entrelaçasse os argumentos parciais dos momentos anteriores.

Diante do exposto até então, pode-se argumentar acerca do entendimento de que a compreensão dos movimentos teórico/metodológicos que constituem a ATD se complexifica na medida em que as experiências e aprendizagens são ampliadas. Nada se constrói ou estrutura a partir de um único momento, é no revisitar-se e desafiar-se constantemente que os horizontes são ampliados. É como na metáfora, expressa no capítulo quatro do livro da ATD, "as duas faces de Jano", precisamos ser recursivos, 
revisitar vivências e expriências, compartilhar momentos com diferentes coletivos. Por meio desses movimentos nossas paisagens serão diversificadas, novas cores e nuances serão vislumbradas e a criatividade do pesquisador aflora. Criatividade tanto no processo de escrita do metatexto, que migra da descrição para a interpretação rumo a elaboração de metáforas, quanto no delineamento de outros percursos e adaptações dos movimentos de análise, a unitarização e a categorização.

Nesse movimento permeado por desafios e aprendizagens, que constiuem o trabalho com a ATD, emerge o desenvolvimento de um olhar sensível por parte do pesquisador. As sensações e sentimentos afloram, os modos de perceber o mundo e os mecanismos de conservação da realidade são revisitados oportunizando com que a sensibilidade se torne uma aprendizagem.

Estar aberto a compreender o fenômeno em estudo de maneira intensa e profunda provoca o pesquisador a aprender. Nesse exercício o trabalho com a ATD torna-se complexo e desafiador, mas muito prazeroso pois oportuniza conhecer narrativas da realidade interessantes. Dimensão retratada no excerto do diário de pesquisa na sequência:

A análise dos Portfólios através da ATD é bem complexa, porém muito prazerosa. Ler as escritas/reflexões nos Portfólios é muito interessante, já que por inúmeras vezes, além de conhecer algumas histórias de sala de aula bem interessantes os sentimentos ali dispostos são comuns aos meus. Visto que me encontro em formação junto as pessoas que realizam as escritas [DP.M.2(10/06/2010)].

Dentre os desafios, inerentes ao trabalho com a ATD, a escrita assume um papel central, escrevo para pensar e aprender com o que investigo. Por meio do movimento de escrita percebo meus limites e partir do reconhecimento deles procuro me desenvolver, lendo e dialogando com outras pessoas, enfim, ampliando meus horizontres. Essa dimensão, que contempla a relação do trabalho com a ATD e o desafio de escrita, é abordada na escrita abaixo:

Trabalhar com a ATD nos desafia a escrever, a construir bons argumentos e compartilhá-los com leitores externos. Tenho percebido, agora no doutorado, o quanto o trabalho com a ATD oportunizou marcas em minha constituição enquanto professora e pesquisadora. A autoria no processo de escrita pode ser destacada como uma dessas marcas, a percepção acerca dos modos de fazer pesquisa e de como publicizá-la também são elementos marcantes em termos de aprendizagens com a ATD. As teorias emergentes são desafiadoras, mas possibilitam muitas aprendizagens. Como tive contato com muitas pessoas que desonhecem a ATD tive que construir meios de sistematização de meus entendimentos e compartilhar com os demais, além de argumentar acerca da sua relevância [DP.T.1(2018)]. 
Na ATD somos desafiados a, progressivamente, migrar de uma escrita descritiva rumo a uma em nível interpretativo. Como aprendizagens, correlatas ao desenvolvimento da autoria, emerge a apropriação de outras possibilidades de linguagens com a metáfora. A compreensão dos referenciais teórico/metodológicos da ATD nos provoca a aprender acerca da utilização de metáforas como gênero de escrita que interpreta o fenômeno, minimizando a descrição rumo a compreensão.

Mais do que montar quebra-cabeças, com uma paisagem pré-estabelecida, a ATD nos desafia montar nossos mosaicos. O mosaico, diferente do quebra-cabeça é singular, único e impregnado pela subjetividade de seu criador. Inúmeros fragmentos buscam se conectar na intencionalidade de construir uma paisagem, um horizonte único. No exercício de validar sua percepção o autor tenciona tornar compreensível o horizonte, por ele vislumbrado e expresso no mosaico, aos demais que terão contato com o mesmo.

Nesse percurso de aprendizagens com a ATD a apropriação de linguagens como a metáfora foi se intensificando à medida que a compreensão dos referenciais teórico/metodológicos progredia, assim como o desenvolvimento da autoria. Nesse ínterim, ao relatar o processo inerente a análise do material empírico a partir da ATD, a pesquisadora relata em seu texto da dissertação o desenvolvimento de uma metáfora. Como pode ser observado na sequência:

\begin{abstract}
Realizar o processo de análise foi como escalar uma montanha, partindo da base com uma quantidade significativa de informações e a cada nova etapa percorrida maior compreensão e dimensão das informações iniciais eram possibilitadas. Foi um movimento de ir se desprendendo da base da montanha e ir adquirindo a possibilidade de vislumbrar novos horizontes e na chegada ao topo contemplar um horizonte totalmente novo e cheio de múltiplos significados. Chegar ao topo da montanha não foi sinônimo de finalização, mas de fechamento de um ciclo, que se (re)visitado, pode anunciar novas paisagens e proporcionar outras compreensões [T.D.2(2014)].
\end{abstract}

A pesquisadora amplia essa percepção, pontuando a compreensão das categorias como paisagens, sendo esse entendimento oportunizado por meio da apropriação teórico/metodológica da ATD. Como pode-se observar a seguir:

Compreendo as categorias enquanto paisagens, pois demonstram as compreensões dos licenciandos e as minhas enquanto pesquisadora, em um determinado contexto e que com o passar do tempo podem se mostrar de forma diferente (re)significando as compreensões anteriores [T.D.3(2014)].

No entanto, não precisamos, e ousaria dizer nesse momento que não devemos, ficar preocupados em encontrar a metáfora. Ela emerge, aflora a partir da imersão do autor para com o fenômeno em estudo e de como ele se mostra e tem a ensinar. A sensibilidade e passagem da escrita descritiva para interpretativa ocorrem, 
progressivamente, como aprendizagens para o pesquisador. Não devemos nos pressionar, é no processo de transformar as vivências em experiências e de nos permitirmos transformar que tudo acontece. Como argumentam Moraes e Galiazzi (2016), é diante do caos da tempestade que emergem os raios de luz que oportunizam a compreensão e tudo passa a fazer sentido.

Nesse interím, a reflexão construída por Moraes e Galiazzi (2016, p. 255), acerca dessa nuance, nos oportuniza refletir que:

O movimento do semântico ao hermenêutico, característico da ATD, é esforço permanente de construir e expressar novas compreensões sobre os fenômenos investigados. Novos entendimentos não nascem prontos e claros, exigindo seguidamente metáforas para sua expressão, metáforas vivas que tanto ajudam a expressar novas compreensões como a constituí-las.

Ainda sobre as metáforas, sua utilização como recurso linguístico na ATD e no movimento de ampliação dos horizontes compreensivos do pesquisador, os autores ampliam argumentando que:

As metáforas auxiliam o pesquisador a se mover em espaços discursivos desconhecidos, ajudando a aproveitar a intuição e a imaginação e os conhecimentos tácitos do pesquisador na elaboração e comunicação de novos entendimentos construídos ao longo das análises. As metáforas construídas são modos de ampliação de horizontes de compreensão do pesquisador (MORAES; GALIAZZI, 2016, p. 255).

Diante do exposto, pretende-se argumentar acerca da relevância do processo de aprendizagem e apropriação teórico/metodológica da ATD como um percurso formativo e constitutivo do vir a ser pesquisador. Os desafios que constituem os distintos momentos da metodologia supracitada instigam o pesquisador a escrever para pensar, perceber a pesquisa e as dimensões que a constituem por meio de outras perspectivas. Nesse ínterim, a sensibilidade e a escrita se aproximam em termos de aprendizagem na ATD, por meio desse movimento o desenvolvimento de metaforas aflora. É nessa amalgama, entre apropriação teórico/metodológica da ATD, desafio de escrita constante e desenvolvimento da sensibilidade que a autoria do pesquisador é delineada de forma progressiva, rumo a um entendimento mais profundo e intenso dos fenômenos investigados.

\section{0 ponto final...nunca encerra a compreensão}

Para mim, toda compreesão é uma viagem sem fim: chega a alguns portos, se reabastece e volta a partir (KNOBBE, 2014, p. 32). 
Neste momento de escrita e síntese final, sentidos múltiplos emergem do processo de escrita, reflexão e compreensão inerente a ATD, das aprendizagens acerca de tornarse professora/pesquisadora, da autoria e das múltiplas nuances que articulam o seu desenvolvimento e características. Emergem e afloram compreensões, zonas, nuances e cores percebidas nos horizontes que constituem o percurso entre os portos. Permeando todo esse movimento a certeza de que muitas incertezas ainda virão, há ainda muito a aprender, a perceber, entender e compreender. Como ferramentas nesse processo carrego a escrita, a leitura, a interação com os Outros e a compreensão de meu eterno inacabamento. Muitos portos existirão, muitos personagens me auxiliarão no reabastecimento, muito ainda por aprender, compreender é um desafio constante.

A viagem até aqui oportunizou a construção/percepção de mosaicos, paisagens e horizontes acerca do processo de apropriação teórico/metodológica da ATD e sua correlação com o desenvolvimento da autoria e constituição do vir a ser professor/pesquisador ancorados por uma nuance estética e humanizada da pesquisa de natureza qualitativa. Por meio do exercício, sistemático e progressivo, de escrita a ATD oportuniza ao pesquisador cenários para desenvolvimento da autoria. Construção de argumentos alicerçados diante da complexificação de seus entendimentos e do que o fenômeno, foco do estudo, se mostra e tem a ensinar.

$\mathrm{Na}$ passagem de uma escrita descritiva para interpretativa, o pesquisador desenvolve sua autoria e sensibilidade. Do exercício e desafio constante de se assumir aprendente e inacabado transforma suas vivências em experiências e se apropria teórica e metodologicamente da ATD. Da amalgama entre apropriação dos princípios teórico e metodológicos da ATD e o desafio constante de escrita emerge a aprendizagem, a sensibilidade e o desenvolvimento da autoria. A cada porto uma parada, um reabastecimento e a coragem para migrar rumo a novos e desconhecidos horizontes. Afinal, parar não é uma opção. Viajar é preciso, novos portos e horizontes precisam ser conhecidos. Desse movimento muitas metáforas e escritas emergirão.

\section{Referências}

KNOBBE, M. M. O que é compreender?: viajando com Gulliver por velhos e novos mundos, em companhia de Edgar Morin, Hans-Georg Gadamer, Maria da Conceção Almeida e outros pensadores de diversas áreas do conhecimento. São Paulo: Livraria da Física, 2014.

MARQUES, M. O. Escrever é preciso: o princípio da pesquisa. 2. ed. Petrópolis: Editora Vozes, 2008. 
MORAES, R. A educação de professores de ciências: uma investigação da trajetória de formação e profissionalização de bons professores. 1991. Tese (Doutorado em Ciências Humanas) - Faculdade de Educação, Universidade Federal do Rio Grande do Sul, Porto Alegre, 1991.

MORAES, R. Análise de conteúdo. Educação, Porto Alegre, XXII, n. 37, p.7-21, mar.1999.

MORAES, R. Ninguém se banha duas vezes no mesmo rio: currículos em processo permanente de superação. In: MORAES, R.; MANCUSO, R. (org.). Educação em Ciências: produção de currículos e formação de professores. 2. ed. Ijuí: Ed. Unijuí, 2006. p. 15- 31.

MORAES, R.; GALIAZZI, M. do C. Análise Textual Discursiva. 3. ed. Ijuí: Ed. Unijuí, 2016.

PEREIRA, M. V. A estética da professoralidade: um estudo interdisciplinar sobre a subjetividade do professor. 1996. Tese (Doutorado em Supervisão e Currículo) - Pontifícia Universidade Católica de São Paulo, São Paulo, 1996.

Recebido em: 20 de outubro de 2020.

Aceito em: 21 de novembro de 2020. 